American Journal of Applied Sciences 8 (7): 675-680, 2011

ISSN 1546-9239

(C) 2011 Science Publications

\title{
Improvement of the Thermal, Photo and Mechanical Properties of Poly (Vinyl Chloride) in Presence of Poly (Glycidyl Methacrylate)
}

\author{
Abir S. Abdel-Naby \\ Department Chemistry, Faculty of Science, Fayium University, Egypt
}

\begin{abstract}
Problem statement: Poly (vinyl chloride) suffers from poor heat stability. The thermal degradation of the polymer leads to the evolution of hydrogen chloride gas, extensive discoloration of the polymer and lowering of physical and mechanical properties. Approach: Binary blends of Poly (Vinyl Chloride) (PVC) and Poly (Glycidyl Methacrylate) (PGMA) have been prepared by solution blending aimed at the improvement of thermal and mechanical properties. Results and Conclusion: Thermal properties of the blends were studied using Scanning Calorimetry (DSC), Thermogravimetry (TGA) and potentiometric rate of dehydrochlorination. The increase of the PGMA content in the blend leads to thermal stability of the blend as shown from the thermogravimetry and the rate of dehydrochlorination results. All blends exhibited one major glass transition temperature (Tg) whose position on the temperature scale was lowered with increased level of PGMA. The miscibility of blends was also confirmed by the use of Scanning Electron Microscope (SEM). The improvement of the mechanical properties of various blends of the two polymers was also obtained.
\end{abstract}

Key words: Vinyl chloride, glycidyl methacrylate, Thermogravimetry (TGA), Scanning Electron Microscope (SEM), mechanical properties, thermal stability, hydrogen chloride gas, thermal degradation

\section{INTRODUCTION}

Poly (vinyl chloride) suffers from poor heat stability. The thermal degradation of the polymer leads to the evolution of hydrogen chloride gas, extensive discoloration of the polymer and lowering of physical and mechanical properties (Braun, 1981; Ramli and Dawood, 2010; Ivan et al., 1980). Aiming at the improvement of this thermal stability, many classes of thermal stabilizers are known, including soap stabilizers (Vymazal et al., 1983; 1984; Naqui et al., 1984), organo tin stabilizers and fully organic stabilizers (Banzato et al., 2010; Mohamed and Al-Magribi, 2003; Yassin et al., 1991). Different methods of using these stabilizers are either addition (Sabaa et al., 2005; 2006; Abdel-Naby and Al Dossary, 2008a; Abdel-Naby et al., 2010) to the polymer or chemical modification of the polymer to displace the labile sites by more stable stabilizer moieties (Starnes et al., 1997; Abdel-Naby and Youssef, 1998; Abdel-Naby, 1999) Grafting copolymerization (Abdel-Naby 2001; Abdel-Naby and Al Dossary, 2008b) or blending with other polymer (Abdel-Naby and Al Dossary, 2009; Abdel-Naby and El-Hefnawy, 2003) are the most used methods. These last two methods possess the advantage that the stabilizing moieties are polymeric in nature which helps the compatibility between the polymer and the stabilizer moieties as well as the improvement of the mechanical properties (Mohamed and Sabaa, 1999). In the present work, a trial has been made to prepare a new PVC blend system, namely PVC/PGMA. The choise of PGMA is based on the chemical structure, which gives self-plasticization for PVC

\section{MATERIALS AND METHODS}

Materials: PVC K70 from Al-Ameria company, Egypt, Cadmium-Barium stearate (cd-Ba-st) from G.Siegle, Dibutyl-tin-mercaptide (DOTM) from Ciba Geigy, Dibasic lead sulfate (DBLS) from National lead company, Glycidyl methacrylate from Aldrich, THF from Aldrich, were used.

Synthesis of PGMA: Poly (glycidyl methacrylate) (PGMA) were prepared from glycidyl methacrylate in THF using Azobisisobutyronitrile as initiator according to the method described by Park (2003) $M_{w}=126,400$.

Preparation of polymer blends: The binary polymer blends were made in THF by mixing PVC solution in THF and PGMA in THF (to form 5\% wt/wt). The homogeneous mixed solution was cast into a dry, clean Pyrex Petri dish of known diameter. The film formed on 
complete evaporation of the solvent at room temperature was then dried in a vacuum oven at $50^{\circ} \mathrm{C}$ to constant weight. All films prepared in this way were $0.5 \mathrm{~cm}$ thick.

\section{Method of measurements:}

Thermogravimetry (TGA): TGA measurements were performed on a Shimadzu TG-50 $\mathrm{H}$ in nitrogen atmosphere at a heating rate of $10^{\circ} \mathrm{C} \min ^{-1}$ and a heating range from room temperature to $500^{\circ} \mathrm{C}$. The gas flow rate was $25 \mathrm{~mL} \mathrm{~min}^{-1}$.

Differential Scanning Calorimetry (DSC): DSC measurements were performed on a Shimadzu DSC$50 \mathrm{H}$ in nitrogen atmosphere at a heating rate of $30^{\circ} \mathrm{C}$ $\mathrm{min}^{-1}$ at a gas flow rate of $25 \mathrm{~mL} \mathrm{~min}$. The glass transition temperature $\left(\mathrm{T}_{\mathrm{g}}\right)$ was taken as the mid-point of the transition.

Mechanical properties: Mechanical properties of the polymer blends films were measured on a Shimadzu Autograph in air at room temperature.

Determination of the rate of dehydrochlorination: The rate of dehydrochlorination was measured by a continuous potentiometric determination of the evolved hydrogen chloride gas at $180^{\circ} \mathrm{C}$ in air (Vymazol et al., 1974).

Determination of the photo-degradation: Photodegradation was effected by $\lambda=365 \mathrm{~nm}$ ultra violet lamp from which the sample was held at a constant distance of $15 \mathrm{~cm}$.

The film of the blended sample was preirradiated by a shorter wavelength $\lambda=250 \mathrm{~nm}$ for $10 \mathrm{~min}$ according to the method described by Torkai and Hasegawa (1999), because the main-chain scission of PVC and degradation product are accelerated under the longer wavelength radiation by preirradiation at shorter wavelength.

After photo-irradiation, the whole film is dissolved in THF in a given constant concentration for the UV/visible analysis using Perkin-Elmer lambda 4 UV/visible spectrophotometer. The rise in the absorbance coefficient $\Delta \mathrm{a}$ with the increase of irradiation time was determined for selected peaks according to Kaminska and Kaezmarek (1987):

$\Delta \mathrm{a}=\frac{\Delta \mathrm{A}}{\mathrm{d}}=\frac{\mathrm{A}_{\mathrm{t}}-\mathrm{A}_{0}}{\mathrm{~d}}$

Where:

$\mathrm{A}_{\mathrm{o}}=$ Absorbance of nonirradiated sample

$A_{t}=$ Absorbance of the same sample after irradiation time $t$

$\mathrm{d}(\mathrm{m})=$ Thickness of the PVC /PGMA films
Morphology: Scanning Electron Micrographs (SEM) were obtained by JEOL JSM35-CF scanning microscope.

\section{RESULTS AND DISCUSSION}

Investigation of the compatibility of the polymer blends: Results of DSC scans of homopolymers and polymer blends (PVC/ PGMA) are summarized in Table 1 . The $T_{g}$ of the PVC phase shifts towards lower temperatures as the PGMA content is increased. The data clearly reveal the compatibility between the two polymers as shown from the single $\mathrm{T}_{\mathrm{g}}$ value for the selected ratio of blend. Moreover, the surface morphology of the blended film using SEM also confirms the compatibility of the two polymers (Fig. 1).

\begin{tabular}{lc} 
Table 1: Glass transition $\mathrm{T}_{\mathrm{g}}$ of various PVC/PGMA blends & \\
\hline PVC/PGMA (Wt \%) & $\mathrm{T}_{\mathrm{g}}$ \\
\hline $100 / 0$ & 85 \\
$95 / 5$ & 80 \\
$90 / 10$ & 74 \\
$85 / 15$ & 70 \\
$80 / 20$ & 66 \\
$0 / 100$ & 63 \\
\hline
\end{tabular}

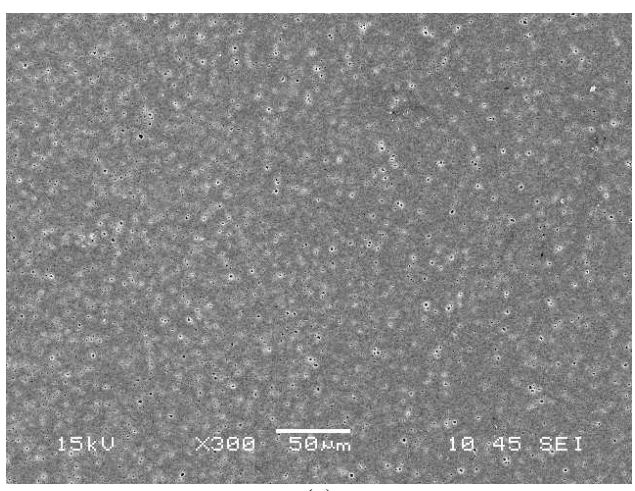

(a)

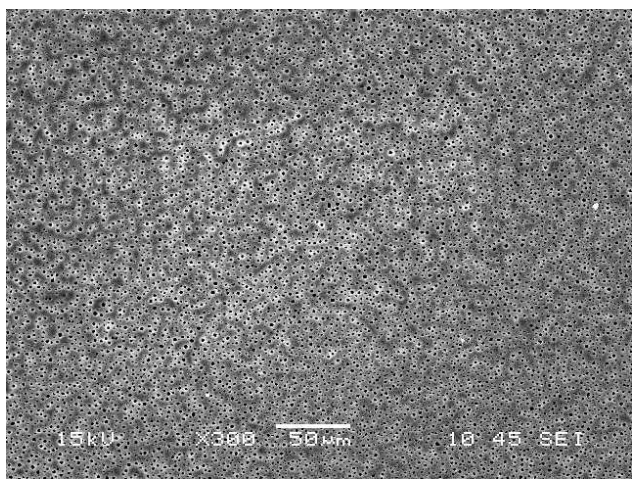

(b)

Fig. 1: Morphology of (a) 5\% PGMA/95\% PVC blended film and (b) $15 \%$ PGMA/85\% PVC blended film 


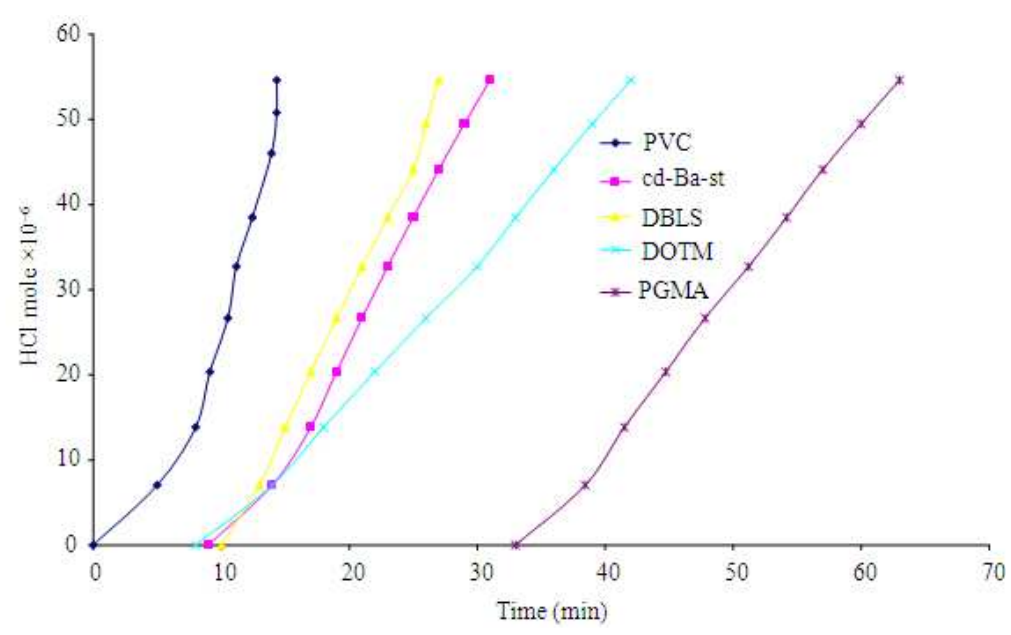

Fig. 2: Dehydrochlorination rate of PVC stabilized with industrially known stabilizers compared with the PGMA and the non-stabilized polymers, in air, at $180^{\circ} \mathrm{C}$

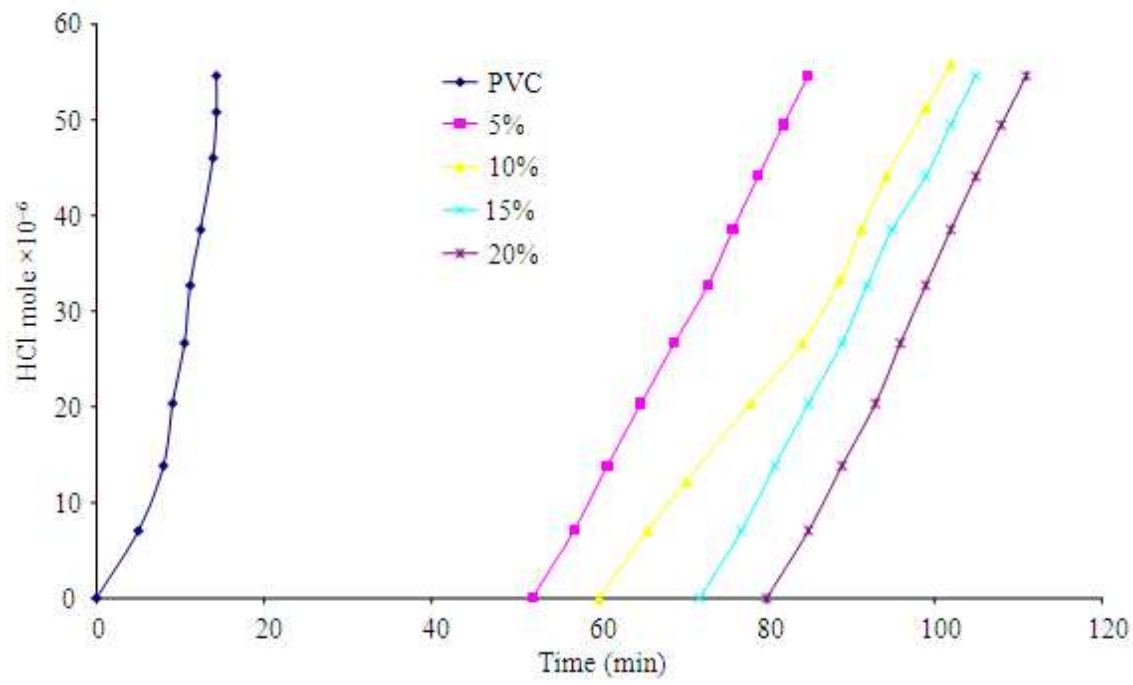

Fig. 3: Rate of dehydrochlorination of various PVC/PGMA blends at in air, at $180^{\circ} \mathrm{C}$

The ratios of PVC / PGMA are chosen so as to keep a high ratio of $\mathrm{PVC}$ in the blend as the aim of the study is to improve the PVC properties in the presence of small amounts of PGMA.

Thermal properties of PVC in presence of PGMA: The kinetics of the thermal degradation in presence of PGMA as compared with known stabilizers (2 mg of the stabilizers is mixed with $100 \mathrm{~g}$ PVC) are represented in Fig. 2. The results show the retardation of the thermal degradation in the presence of PGMA as compared to the industrial stabilizers. This can be seen from the induction period, $\mathrm{T}_{\mathrm{s}}$, during which no detectable amount of $\mathrm{HCl}$ gas is evolved. The $\mathrm{T}_{\mathrm{s}}$ is 33 min in presence of PGMA while it is lower in the presence of cd -Ba-st $(9 \mathrm{~min})$, DOTM $(8 \mathrm{~min})$ and DBLS (10 min). The non-stabilized sample is also given for comparison.

The stabilizing efficiency of PGMA encouraged the blend of PVC with low ratios of PGMA. Figure 3 represents the rate of dehydrochlorination of $\mathrm{PVC}$ blended with 5, 10, 15 and $20 \%$ of PGMA. The blended samples (in the powder) form are taken in such a way as to keep a constant amount of PVC subjected to thermal degradation (Table 2). The results clearly show the increase in the thermal stabiblity of PVC as the ratio of PGMA increases. 
Am. J. Applied Sci., 8 (7): 675-680, 2011

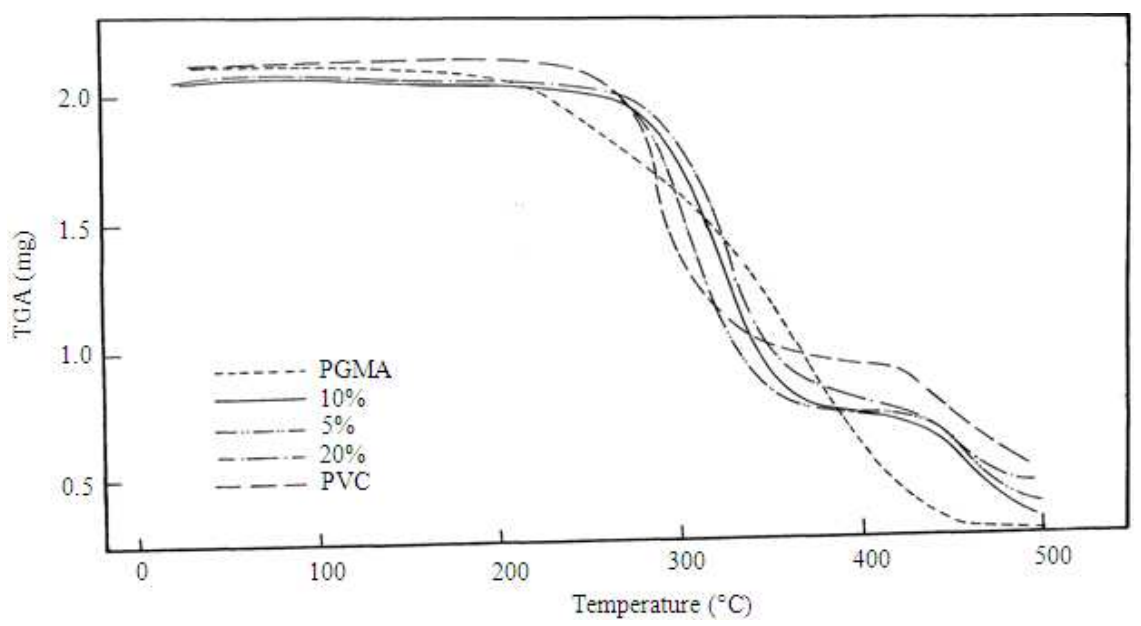

Fig. 4: Thermogravimetric (TG) analysis of various PVC/PGMA blends

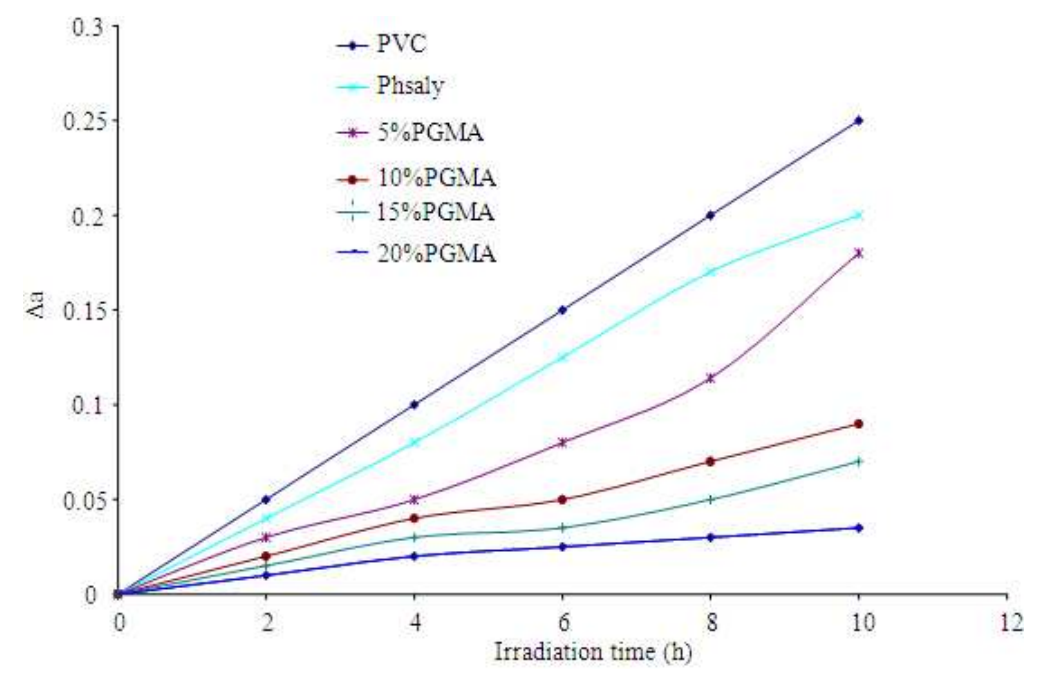

Fig. 5: Change of absorbance coefficient with irradiation time of various PVC/PGMA blended films

Table 2:Amount of PVC/PGMA blends taken for the thermal degradation investigation

\begin{tabular}{ll}
\hline $\begin{array}{l}\text { PVC/PGMA } \\
\text { blends (Wt \%) }\end{array}$ & $\begin{array}{l}\text { Weight taken for thermal } \\
\text { degradation }(\mathrm{g})\end{array}$ \\
\hline $100 / 0$ & 0.2 \\
$95 / 5$ & 0.21 \\
$90 / 10$ & 0.22 \\
$85 / 15$ & 0.24 \\
$80 / 20$ & 0.25 \\
\hline
\end{tabular}

Table 3: The induction period $\left(\mathrm{T}_{\mathrm{s}}\right)$ as a function of PGMA content of various VC/PGMA blends

\begin{tabular}{llll}
\hline Stabilized PVC & & PVC/PGMA & \\
\hline Non-stabilized sample & 0 & $100 / 0$ & 0 \\
Cd-Ba-St & $\mathrm{T}_{\mathrm{s}}(\mathrm{min})$ & blends $\mathrm{Wt} \%$ & $\mathrm{~T}_{\mathrm{s}}$ (min) \\
DBTM & 9 & $95 / 5$ & 52 \\
DBLS & 8 & $90 / 10$ & 60 \\
PGMA & 10 & $85 / 15$ & 72 \\
\hline All the & 33 & $80 / 20$ & 80 \\
\hline
\end{tabular}

All the stabilizers were used in concentration of $2 \mathrm{mg} / 100 \mathrm{~g}$ PVC
This is shown from induction period values as well as the lower rate of degradation (Table 3). The effect of blending PGMA on the thermal stability of PVC was also studied using the thermogravimetric technique, under nitrogen. Figure 4 represents the TG curves for various blended samples. The results reveal an increase in the thermal stability with the increase of the PGMA content. The initial decomposition temperature $\left(\mathrm{T}_{\mathrm{o}}\right)$ of the PVC blended with $20 \%$ PGMA was $320^{\circ} \mathrm{C}$ as compared to unblended $\mathrm{PVC}\left(220^{\circ} \mathrm{C}\right)$. The results seem to be reasonable due to the effect of dilution of PVC by PGMA molecules which minimize the possible cross dehydrochlorination reaction in addition to the possible incorporation of some moieties of PGMA into the PVC chains. 
Am. J. Applied Sci., 8 (7): 675-680, 2011

Table 4: Mechanical properties of various PVC/PGMA blends

\begin{tabular}{llll}
\hline PVC/PGMA (Wt \%) & Tensile strength $\left(\mathrm{N} \mathrm{mm}^{-2}\right)$ & Elongation at break $(\%)$ & Elastic modulus $\left(\mathrm{N} \mathrm{mm}^{-2}\right)$ \\
\hline $100 / 0$ & 28.7 & 18.2 & 422.8 \\
$95 / 5$ & 22.3 & 28.1 & 402.9 \\
$90 / 10$ & 20.8 & 31.1 & 399.3 \\
$85 / 15$ & 18.7 & 34.5 & 394.5 \\
$80 / 20$ & 16.3 & 38.9 & 392.8 \\
\hline
\end{tabular}

Influence of UV irradiation: The influence of UV irradiation on the blended samples PVC/PGMA compared to $100 \%$ PVC is shown in Fig. 5. As the thickness of all films (d) is kept constant, the absorbance coefficient $\Delta$ a could be reduced to $\Delta \mathrm{a}=$ $\Delta \mathrm{A}=\left(\mathrm{A}_{\mathrm{t}}-\mathrm{A}_{\mathrm{o}}\right)$ while, $\mathrm{A}_{\mathrm{t}}=$ Absorbance of the blended film after time $t, A_{o}=$ Absorbance of non-irradiated film. Figure 5 showed that PVC/PGMA samples possessed lower $\Delta \mathrm{a}$ value than the reference UV stabilizer, phenyl salicylate, for a given irradiation time interval. Thus all the blended samples possessed higher photostabililizing efficiency than phenyl salycilate. The increase in the photostability increased with the increase of the PGMA content.

Measurement of mechanical properties: Obtaining good mechanical properties of the polymeric sample is also our object. Table 4 represents the detailed stress/strain data of PVC and the blends. These data are an average from three runs for ultimate tensile strength, Young's modulus and elongation at break. The results show the effect of increasing the PGMA content in the blended films is lowering of the tensile strength and increasing the elongation at break. These results are in good agreement with the plasticization role played by PGMA in the blended films which lowered to a great extent the intermolecular hydrogen bonding between the PVC molecules.

\section{REFERENCES}

Abdel-Naby, A. and A. Al Dossary, 2008a. Inhibition of the thermal degradation of rigid Poly (vinyl chloride) by dienophilic compounds. J. Vinyl Addit. Technol., 14: 175-183. DOI: 10.1002/vnl..20165

Abdel-Naby, A. and A. Al Dossary, 2008b. Use of N(N'- Arylamino)maleimides to Improve the thermal properties of Poly(vinyl chloride) Through Chemical Modification and Graft Copolymerization. J. vinyl Addit. Technology, 14: 167-174. DOI: $10.1002 /$ vnl..20159

Abdel-Naby, A. and A. Al Dossary, 2009. Stabilization of Poly(vinyl chloride) Using Dienophilic Compounds. J. Applied Polym. Sci., 114: 32183228. DOI: 10.1002/app
Abdel-Naby, A. and A. Youssef, 1998. Inhibition of the Degradation of Poly(vinyl chloride) by its modification With 5-Pyrimidine Carbonitrile(1,2,3,4-tetrahydro-4-oxo-6-phenyl=2thioxo). Polymer Int., 46: 336-338. DOI: $10.1002 /(\mathrm{SICI}) 1097-$

0126(199808)46:4<336::AID-PI34>3.0.CO;2-B

Abdel-Naby, A. and M. El-Hefnawy, 2003. Improvement of the Thermal and Mechanical Properties of Poly(vinyl chloride) in presence of poly(ethylene succinate). Polymer Test., 22: 25-29. DOI: 10.1016/S0142-9418(02)00044-2

Abdel-Naby, A., 1999. Stabilization of Rigid Poly(vinyl chloride) by 5,6,7,8-Tetrahydro-2-Mercapto-4- ( p-Methoxyphenyl)-3-Quinolinecarbonitrile. J. Vinyl Additive Technol., 5: 159-164. DOI: $10.1002 / \mathrm{vnl} .10326$

Abdel-Naby, A., 2001. Gamma-radiation-Induced graft Copolymerization of $\mathrm{N}$-[4-(N-substituted amino carbonyl)phenyl] maleimide onto Poly(vinyl chloride) films. J. Vinyl Addit. Technology, 7: 244-249.

Abdel-Naby, A., R. Al-Ghamdi and A. Al-Ghamdi, 2010. Effect of Cyanoguanidine-Metal and UreaMetal Complexes on the thermal Degradation of Poly(vinyl chloride) J. Additive Technol., 16: 1522. DOI: $10.1002 / \mathrm{vnl} .20225$

Banzato, C., V. Massimo, C. Fiorucci, B. Vigna and S. Papale, 2011. Hydrogeological prognosis with regard to realisation of the new colle Di tenda road tunnel. Am. J. Environ. Sci., 7: 1-14. DOI: 10.3844/ajessp.2011.1.14

Braun, D., 1981. Thermal Degradation of Poly. In: Development in Polymer Degradation, Grassie, N., (Ed.). Elsevier Science and Technology, London, pp: 294. ISBN: 10: 0853347395

Ivan, B., T.T. Nagy, T. Kelen, B. Turscanyi and F. Tudos, 1980. Crosslinking and scission in hermooxidative degradation of PVC. Polym. Bulletin, 2: 83-88. DOI: 10.1007/BF00275558

Kaminska, A. and H. Hasegawa, 1987. Effect of copolymers modifying PVC on its physical and mechanical properties and its UV-radiation resistance ${ }^{\dagger}$. VIII. Thermal and photochemical stability of PVC films containing polystyrene and their permeability. Die Angew. Macromolek. Chem, $\quad$ 148: 93-102 DOI: $10.1002 / \mathrm{apmc} .1987 .051480109$ 
Mohamed, N. and M. Sabaa, 1999. Thermal degradation behaviour of poly(vinyl chloride)poly(vinyl butyral) blends. Eur. Polymer J., 35: 1731-1737. DOI: 10.1016/S0014-3057(98)002572

Mohamed, N. and W. Magribi, 2003. N-(Sbstituted phenyl) itaconimides as organic stabilizers for rigid Poly(vinyl chloride) against photo-degradation. Polymer Degrad. Stab, 82: 421-433. DOI: 10.1016/S0141-3910(03)00194-0

Naqui, M.K., P.A. Unnikrishnam, Y.N. Sharma and I.S. Bhardwaj, 1984. Effect of calcium and zinc carboxylates on the thermal stabilisation of PVC. Eur. Polym. J., 20: 95-98. DOI: 10.1016/00143057(84)90231-3

Ramli, M. and E.T. Dawood, 2010. Effects of palm fiber on the mechanical properties of lightweight. Am. J. Eng. Applied Sci., 3: 489-493. DOI: 10.3844/ajeassp.2010.489.493

Sabaa, M., E. Oraby, A. Abdel-Naby and R. Mohamed, 2005. Anthraquinone derivatives as organic stabilizers for rigid Poly(vinyl chloride) against photo-Degradation. Eur. Polym. J., 41: 2530-2543. DOI: 10.1016/J.EURPOLYMJ.2005.05.015

Sabaa, M., E. Oraby, A. Abdel-Naby and R. Mohamed, 2006. Organic thermal stabilizers for rigid Poly(vinyl chloride). Part XI: Anthraquinone derivatives. Polymer Degrad. Stab., 91: 242-254. DOI: 10.1016/j.polmdegradstab.2005.05.011

Starnes, W. H., Jr., J. A. Wallach and H. Yao, 1997. Six-center concerted mechanism for poly(vinyl chloride) dehydrochlorination. Macromolecules, 30: 676-679. DOI: 10.1021/ma9520252
Torkai, A. and H. Hasegawa, 1999. Accelerated photodegradation of poly(vinyl chloride). Polym. Degrad. Stab., 63: 441-445. DOI: 10.1016/S01413910(98)00125-6

Vymazal, Z., K. Volka, M. W.Sabaa and Z. Vymazalova, 1983. Effect of stabilizers in the thermal treatment of PVC-XIII: Study of the stabilization efficiency of combinations of BA and ZN stearates in PVC. Eur. Polym. J., 19: 63-69. DOI: 10.1016/0014-3057(83)90103-9

Vymazal, Z., Z. Vymazalova, K. Volka, T. Goght and M. Karvas, 1984. Effect of stabilizers in the thermal treatment of PVC-XVI: Study of the stabilization efficiency of antimony tris(isooctyl thioglycolate) in PVC Eur. Polym. J., 20: 879882. DOI: 10.1016/0014-3057(84)90167-8

Vymazol, Z., E. Czako and B. Meissner, 1974. Déhydrochloruration du PCV en utilisant une correction pour des conditions isothermes. J. Applied Polymer Sci., 18: 2861-2863. DOI: 10.1002/app.1974.070180927

Yassin, A., M. Sabaa and A. Abdel-Naby, 1991. Cyanoguanidine and its complexes as Thermal Stabilizers for rigid Poly(vinyl chloride). Polym. Degrad. Stab., 31: 189-202. DOI: 10.1016/01413910(91)90074-2 